\title{
Using e-portfolios in a field experience placement: Examining student-teachers' attitudes towards learning in relationship to personal value, control and responsibility
}

\author{
Ronnie H. Shroff, John Trent, and Eugenia M. W. Ng \\ The Hong Kong Institute of Education, Hong Kong
}

\begin{abstract}
This study extends the ownership of learning model by using e-portfolios in a field experience placement to examine student-teachers' attitudes towards learning in relationship to personal value, feeling in control and taking responsibility. A research model is presented based on research into ownership of learning. The student e-portfolio ownership of learning questionnaire (SEOLQ) was developed. Seventy-seven participants completed the survey measuring their responses to ownership of learning components of attitudes towards learning (ATL), personal value (PV), feeling in control (FIC), and taking responsibility (TR). Data were used to test the hypotheses postulating the main effects of ATL using e-portfolio on the constructs PV, FIC, and TR. The results of the study indicated that ATL had a significant influence on PV, FIC and TR. The results suggest the student-teachers valued the integration of the e-portfolio into the field experience and developed a sense of control of their learning. Responsibility-related findings suggest that participants were sensitive to both the means of manipulating the e-portfolio and the results of their efforts doing so. By providing student-teachers with the opportunity to reflect critically upon their work as educators, e-portfolios can serve as an invaluable resource for promoting effective ownership of learning.
\end{abstract}

\section{Introduction}

The adoption of educational portfolios has been increasing for some time, particularly over the past seven years (Deneen \& Shroff, 2010; Lorenzo \& Ittelson, 2005; Shroff, Ng, \& Deneen, 2011; Trent \& Shroff, 2012). The utilization of electronic portfolios (e-portfolios) has the potential to change the nature of learning environments and the ways in which student learning is promoted through different modes of learning (Ayala, 2006). E-Portfolios allow information to be stored, accessed, updated, and presented in various electronic formats as a record or evidence of student learning and achievement (Chau \& Cheng, 2010; Gaide, 2006). However, there are a wide range of interpretations around what comprises an e-portfolio, to the extent that definitions and purpose will vary because e-portfolios can be utilized in multiple ways and for different reasons by students, faculty, staff and administrators. As such, there is no uniform definition of e-portfolios (Hallam \& Creagh, 2010).

From a pedagogical perspective, e-portfolios serve to provide a repository of work on which to base subsequent evaluation of students' knowledge, skills, and dispositions relative to their academic programme. For example, a student-teacher engaged in a field experience can showcase audio clips of his or her classroom practice. These types of items, called artefacts, can be chosen to represent the student's growth and development as an educator over time and to provide evidence of high quality work the student has performed prior to graduation from the programme. Hence, an e-portfolio provides a selection of specific artefacts from which evaluation or assessment of specific outcomes may take place and subsequently offers a medium for students to engage in, document evidence of reflective practice and take ownership of their learning (Tubaishat, Lansari, \& Al-Rawi, 2009). Potentially e-portfolios can be used as a tool to enable students to effectively capture and record different aspects of the learning process for reflection and/or continuous assessment (Gaide, 2006). Moreover, the e-portfolio can also become a part of a dynamic and collaborative reflective practice through reflection on and in action (Schön, 1987). As well as presenting evidence from a single course or programme, individual students can also use the evidence or reflections of their learning held in their e-portfolio to present a wide range of their achievements (Abrami \& Barret, 2005).

Recent discussions emanating from academic debate and research surround the value of e-portfolios as a resource for helping pre-service teachers document their work towards meeting professional standards and assisting reflection on their teaching practice (Abrami \& Barret, 2005; Ayala, 2006). Goldsby and Fazal (2000) observed that student teachers who work with e-portfolios are more likely to use technology in their teaching and that such teachers are more effectively able to create meaningful learning 
experiences using technology in their lessons. Numerous studies provide evidence that learners feel more confident and positive towards their learning on using e-portfolios (Hussein, 2009; Shroff, Ng, \& Deneen, 2011; Wright, Stallworth, \& Ray, 2002; Zhang, Olfman, \& Ractham, 2007). E-portfolio development allows the learner to take control of the portfolio content. The learner decides how much writing and reflection to document in his or her portfolio content. Hence, a portfolio's support for reflective thinking is one of its most defining pedagogical features (Kong, Shroff, \& Hung, 2009; Orland-Barak, 2005).

Specifically, this study's literature review integrates and synthesizes content regarding (a) electronic portfolios and (b) ownership for learning. The objective of this study is to construct a more comprehensive ownership of learning model by examining student-teachers' attitudes towards learning in relationship to personal value, feeling in control and taking responsibility in a field experience placement. We frame our inquiry into and understanding of students' perceptions for ownership of learning with an adaptation of Milner-Bolotin's (2001) theoretical framework. The relevance of this study is that a stronger theoretical basis could prove enormously beneficial since it would have the potential to provide a framework for guiding future research by identifying key research variables and relationships. It is believed that ownership of learning theory may provide important clues as to how e-learning technologies can become powerful catalysts for change as well as tools for redesigning our learning and instructional systems (Martens, Gulikers, \& Bastiaens, 2004). The development of a framework could effectively lead student-teachers to reflect on their teaching, analyse their strengths and weaknesses, and set goals for continued improvement. This review represents the basis for the development of a theoretical framework and hypotheses of the present study.

\section{Background}

\section{E-Portfolios}

Recently, e-portfolios have emerged in post-secondary institutions as a means for assessing and promoting student's skills and competencies (Cambridge, 2010). The electronic portfolio is a digitized, flexible, owner-centric evidenced-based tool that encourages students to take ownership and responsibility for their learning. By making explicit the process of using an e-portfolio tool that encourages students to engage in a process of continuous reflection, students are able to select, categorize and document their achievements and accomplishments for review and assessment related to their professional development (Gaide, 2006). This process not only helps to provide direction to a student's personal and professional life but also provides students with an opportunity to display their learning electronically in an organized format. Moreover, this process enables students to create intellectual order and generate new mental pathways that define the way they think and learn, thereby authoring their own intellectual identities (Vogel, Davison, \& Shroff, 2001).

A portfolio's support for reflective thinking is its most defining pedagogical feature (Ellsworth, 2002). Research has shown that the process of constructing an e-portfolio stimulates students to engage in reflective thinking and subsequently self-evaluate and consider their learning (Cambridge, 2010; Wade, Abrami, \& Sclater, 2005; Wang, 2009). The e-portfolio can also be a powerful tool to 1) promote learning (including learning from the process of assembling the portfolio); 2) improve critical thinking and content areas; 3) record accomplishments in an educational context held by the students for their own use; 4) assess long term, ongoing, authentic evaluation, and self-evaluation and self-reflection, and 5) provide evidence of continuous development (Orland-Barak, 2005; Pelliccione \& Raison, 2009).

E-Portfolios may also address challenges in educational processes. Herremans and Murch (2003) identified two difficulties learners encounter in a professional degree programme: firstly, taking their experiences and determining what they have learned from those experiences; and secondly, taking responsibility for their own learning. E-Portfolio development may address these difficulties by allowing the learner to take control of and reflect on course content and work product (Stefani, Mason, \& Pegler, 2007). The learner evaluates their work, explicitly reflects on that work and potentially articulates a meta-dialog on the evaluative process (Mansvelder-Longayroux, Beijaard, \& Verloop, 2007). Hence, reflective thinking is a defining pedagogical feature. E-Portfolios extend the diversity for work product and reflection by increasing the breadth of materials that may be included, and the potential for dynamic ongoing interaction and reflection (Wickersham \& Chambers, 2006). 
Bauer and Dunn (2003) further discussed the importance on the value of the portfolio process by stating, "The real strength of the e-portfolios is the activities in which the students are engaged. Through continuous reflection, accumulation and selection of artefacts, and receipt of feedback, students are developing valuable skills that will serve them as professional educators" (p. 17). Berg and Lind (2003) also emphasized the value of the experiences students encountered while developing their e-portfolios and found evidence to suggest that constructing e-portfolios not only facilitated reflective practice but led students to assess their own learning. Gatlin and Jacob (2002) describe e-portfolios as providing a "richer snapshot" of preservice teachers' achievement and expertise as well as being a documentation of their technological skills (p. 35). Because students are able to provide a more complete picture of their abilities using a variety of sources in e-portfolios, they are better able to demonstrate their ownership of learning (Shroff, Deneen, \& Lim, 2012; Stefani, et al., 2007). Similarly, e-portfolios may provide an authentic means to embed technology standards into the assessment process; students can demonstrate ownership of their learning while creating portfolios that document their ability to meet all of the required standards (Armitage, Wilson, \& Sharp, 2004).

\section{Ownership of learning}

Studies using ownership as a theoretical framework can be found in research in different areas such as language learning (Savery, 1996), teacher education (Rainer \& Matthews, 2002), science education (O'Neill \& Barton, 2005) and in instructional technology (Savery, 1996). The concept of ownership has roots in self-regulation (Brown \& Ryan, 2004) in that it views learners as metacognitively, motivationally, and behaviourally proactive participants in their own learning process (Shroff \& Vogel, 2009; Nichol \& Macfarlane-Dick, 2006).

Ownership is a term frequently used in connection with educational goals such as engaging and empowering students in a higher education context (Singleton \& Newman, 2009) as well as in an ICT context (Lim, 2004). Scardamalia and Bereiter (1994) suggest that with ownership of learning, students move into primary responsibility for recognizing what must be learned to accomplish a given task and then setting and evaluating criteria for understanding. Student autonomy is seen as a result of students developing ownership (Rainer \& Matthews, 2002). Learning requires the learner to see meaning and relevance in the experience, and this meaning and relevance will "depend on the degree to which learners are able to make learning their own" (Dudley-Marlin \& Searle, 1995). Ownership of learning is a process, which develops over time and appears to emanate from the following components: finding personal value, feeling in control, taking responsibility and attitudes towards learning (Armitage, et al., 2004; Milner-Bolotin, 2001).

\section{Finding personal value}

Finding personal value is about understanding how the knowledge and skills developed during learning might be useful in situations outside the original learning environment (Armitage, et al., 2004). In order to be motivated, learners need to be engaged by a topic, to see it as important and to feel that they are capable of doing it (Shroff \& Deneen, 2010). Moreover, finding value serves as criteria for monitoring and evaluating their own learning - this is a class of motive that leads the individual to perform acts they think should be done (Milner-Bolotin, 2001). It also refers to a set of stable, general beliefs about what is desirable and these beliefs emerge from the individual's core psychological needs and sense of self (Feather, 1992). As a result, the learner appropriates the strategies based on his or her own skills, needs and experiences. Overall, the use of technology can help sustain value, promote an individual's feelings of competence, and support a focus on the learning process (Gulikers, Bastiaens, \& Martens, 2005). For example, engaging in a process of reflection using an electronic portfolio tool may improve learning outcomes such as critical thinking and problem-solving skills because it encourages an individual to generate knowledge connections (i.e., cognitive constructivism) and independently apply new knowledge and strategies that align with his or her value disposition (Chau \& Cheng, 2010).

\section{Feeling in control}

Control pertains to individual involvement in making decisions and being a proactive rather than a reactive learner (Armitage, et al., 2004). According to Rogers and Freiberg (1994), learning is facilitated when the learner has control over the nature and direction of the learning process. High feelings of control occur when the learner makes decisions and is a proactive rather than reactive learner (Deci \& Ryan, 1987). It is a basic human tendency to seek control of one's environment, such that one is in full control of 
his or her actions, attributes his or her behaviour to stable reasons and is deemed to have choices (deCharms, 1968). Therefore it follows, that individuals' internal control can be enhanced if they are given choices (Iyengar \& Lepper, 1999). The concept of control involves the experience of choice, in other words, the experience of an internal perceived locus of causality, i.e., an individual's perceived ability or effort (Enghag \& Niedderer, 2007). This implies that an individual acts out of choice rather than obligation or coercion (Reeve, Nix, \& Hamm, 2003). Such choices are based on an awareness of his or her desires as well as a flexible interpretation of external events.

\section{Taking responsibility}

Responsibility in learning refers to the learner taking responsibility, or feeling accountable, for the process of learning as well as the results of learning (Enghag \& Niedderer, 2007). Learners can be given increasing amounts of initiative in undertaking a task, choosing the contents and assessing their own work. In this way they will develop a feeling of autonomy for their own learning. The basis of learner autonomy is that the learner takes responsibility for his or her learning (Armitage, et al., 2004). This acceptance of responsibility has both socio-affective and cognitive implications: it entails positive attitudes towards learning as well as the development of a capacity to reflect on the content and process of learning. Aiming towards autonomous learning thus means shifting emphasis onto the learner and allowing more room for taking responsibility (Enghag \& Niedderer, 2007). Wang and Peverly (1986), for example, review findings of strategy research and concluded that autonomous learners are those who have the capacity to take responsibility in the learning process; they are responsible for identifying goals, formulating their own goals, and changing goals to suit their own learning needs and interests.

\section{Attitudes towards learning}

The importance of attitudes towards learning has been investigated by many educational researchers (Ajzen \& Fishbein, 1980; Al-Gahtani \& King, 1999; Ocker \& Yaverbaum, 2002). Affective attitudes reflect emotional reactions and may change after repeated exposure to situations involving the goal for the attitude (Ajzen \& Fishbein, 1980). Cognitive components of attitudes are believed to be more fundamental and constant over time and may have a direct influence an individual's need to find personal value, be in control and take responsibility (Wood, 2000). Cognitive attitudes are difficult to influence but may change when new knowledge is presented; provided the knowledge is convincing and has the potential to provide value (Liddell \& Davidson, 2004). Behavioural attitudes are manifestations of underlying cognitive and affective attitudes. An individual's attitude towards his/her learning requires the task to be within the individual's perception of cognitive ability (i.e., the capacity to perceive reason or use intuition), leading to improved performance, by sharpening cognitive engagement, in all aspects of the task. Moreover, enjoyment is generated by particular conditions and/or objects in the environment that focus attention - it represents an affective reaction (Murphy \& Alexander, 2000).

\section{Research model and hypotheses}

\section{Research Model}

The work by Milner-Bolotin (2001) provides the starting point for the development of our research model and directs the selection of appropriate components of our model. To frame our understanding of ownership of learning, we have adopted a modified version of Milner-Bolotin's (2001) framework of ownership (see Figure 1). In this framework, ownership of learning is broken down into four factors of the learning process: attitudes towards learning (ATL), finding personal value (FPV), feeling in control (FIC), and taking responsibility (TR) (Milner-Bolotin, 2001). Hence, our research model is built on an ownership of learning foundation that pulls elements from Milner-Bolotin's (2001) work and subsequently integrates the construct of attitudes towards learning (ATL) into the framework. Based on the literature review, we believe that the construct of attitudes towards learning (ATL) can reasonably be integrated within Milner-Bolotin's (2001) ownership of learning framework.

\section{Research hypotheses}

Based on Milner-Bolotin's (2001) framework, it is proposed that ATL will have a significant influence on students-teachers' perception of FPV, FIC, and TR.

\section{$H^{I}$ : Student-teachers' ATL using e-portfolio will have a significant influence on their sense of FPV.}


Hypothesis 1 maintains a causal relationship between ATL using e-portfolio and FPV. If an individual believes that he or she is engaged in e-portfolio, because he or she finds it convenient, that individual is more likely to continue to find personal value in it. Individual value gives information about e-portfolio task is within the potential of an individual and whether the task is worth trying. This information may consist of that individual's achievements, characteristics of the e-portfolio tasks performed, information about his or her performances and finally, the reactions of that individual to his or her successes and failures and performance attempts in general. The nature of the e-portfolio may provide a sense of unpressured willingness to engage in the activity, and as such, volition will be high when actions are endorsed fully by the individual such that the individual experiences a sense of personal value.

\section{$H^{2}$ : Student-teachers' ATL using the e-portfolio will have a significant influence on their sense of} FIC.

Hypothesis 2 maintains a causal relationship between ATL using e-portfolio and FIC. E-Portfolio may offer participants control over the initiation and regulation of their behaviour (Tosh, Light, Fleming, \& Haywood, 2005). For example, control over the e-portfolio content may allow student-teachers to showcase their best work in a digitized format and provide choice in how they customize their e-portfolio entries. Choice occurs when an individual perceives control of the selection process from among options of similar values and outcome certainties (Milner-Bolotin, 2001). We expect that the provision of control is likely to be presented as a choice over options and actions (e.g., control concerns what to do, whether to do it, when to do it, how long to do it, when to stop doing it and whether to switch to something else).

\section{$H^{3}$ : Student-teachers' ATL using the e-portfolio will have a significant influence on their TR.}

Hypothesis 3 maintains a causal relationship between ATL using e-portfolio and TR. For instance, allowing an individual to take responsibility on how much effort they choose to engage in facilitates an intention to continue autonomous functioning (Thompson \& Wankel, 1980). As an ownership of learning construct, however, the construct of attitudes towards learning may apply when an individual possesses a sense of responsibility with respect to the action. When autonomy-oriented, individuals take responsibility to make decisions and subsequently regulate themselves in pursuit of self-selected goals. In addition, autonomy can be seen as a responsibility towards learning in which the learner is prepared to take, or does take, responsibility for his/her own learning. To take responsibility for one's own learning essentially concerns decision making about one's own learning. Student-teachers have the freedom to make decisions are thus able to take ownership over their e-portfolios. Having this freedom allows students to explore beyond the norm and take more responsibility for their own learning.

The above hypotheses give rise to the research model (Figure 1) represented as a causal relationship schema and used as a point of departure for this research. The boxes represent the constructs which were measured by a set of items, with arrows representing hypotheses 1 to 3 .

\section{Research method}

\section{Context of the study}

The field experience at Hong Kong Institute of Education (HKIEd) is an important element in teacher education. It provides opportunities for student teachers to teach in real classroom settings before assuming their full responsibilities. The field experience placement at HKIEd is a learning opportunity through which student teachers can critically examine whether learning theories learned in coursework fit into actual teaching situations. Through teaching practice which is properly supported, planned, supervised, student teachers can also take ownership of learning and responsibility for their own professional development. 


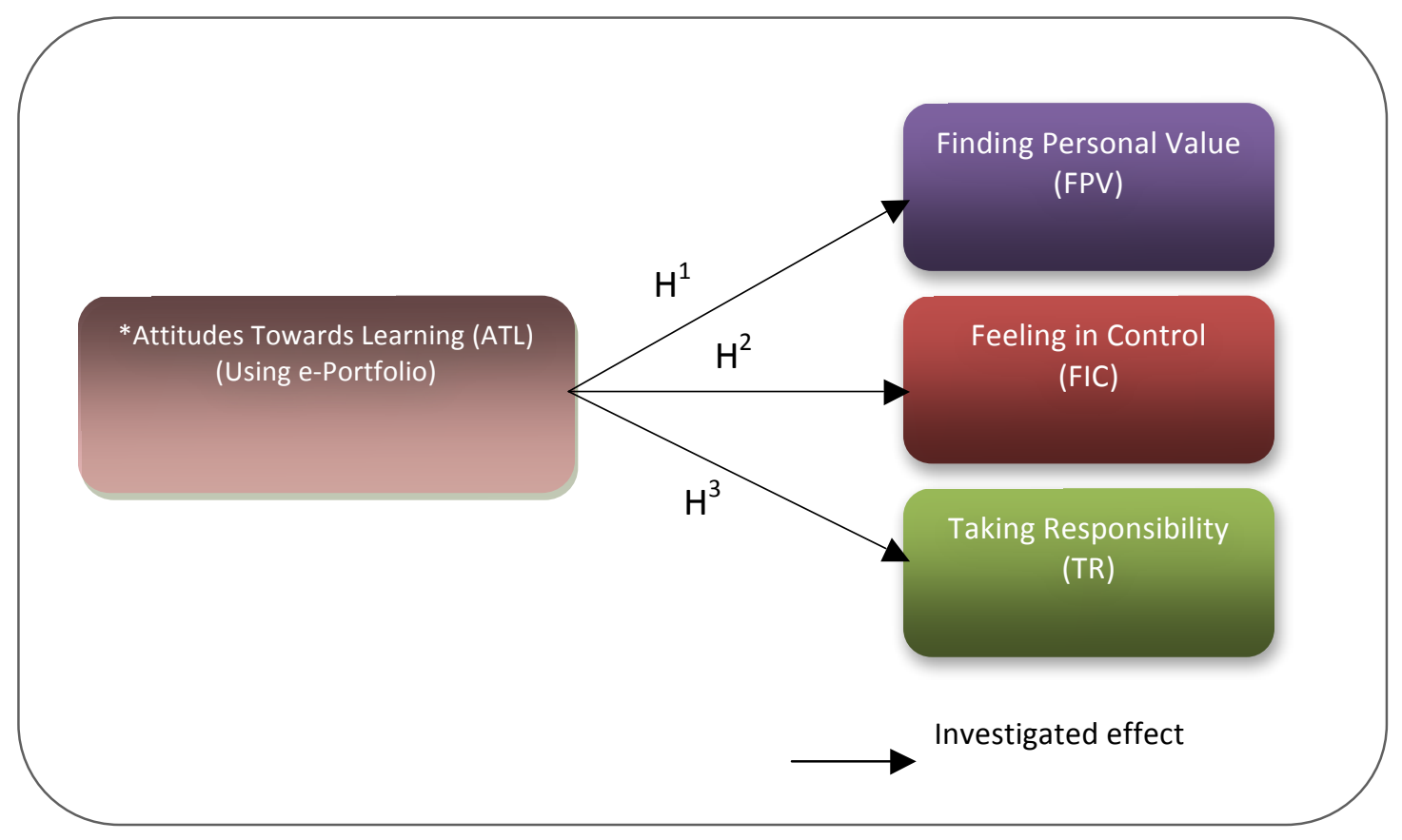

Figure 1. Conceptual ownership of learning research model. Adapted from Milner-Bolotin (2001)

* Integrated into ownership of learning framework for this paper.

\section{Assessment task}

The assessment component of the field experience at HKIEd is the development of a portfolio. The portfolio illustrates student-teachers' ongoing professional development in the relevant domains of teaching. It provides sources of evidence, in addition to observation of teaching and learning, pre-lesson and post-lesson conferences, on the basis of which the supervisor can make informed judgments about the student-teachers level of competence in teaching. The portfolio is a focused and organized documentation of student-teachers' professional development. The construction of the portfolio is a way to facilitate the participant's ongoing reflection about one's professional development in the teacher education programme. Moreover, the focus of the portfolio is to provide a collection of reflections and evidence of continual professional growth of participants. Hence, the portfolio allows student-teachers to provide evidence of good practice that might not have been apparent in the observed lesson (Joyes, Gray, \& Hartnell-Young, 2010).

\section{The research setting}

The field experience e-portfolio pilot commenced in spring 2011, involving a cohort of 77 year 3 field experience student-teachers enrolled in the Bachelor of Education English Language Programme and approximately 20 supervisors. The purpose of the pilot was to: 1) Digitize the existing English Department FE paper-based portfolio using the Mahara digital portfolio platform; 2) Educate these pre-service teachers and their university supervisors about the use of the Mahara platform; 3) Use the pilot findings, addressing the challenges and plan a path for deeper/broader implementation. The selection of the field experience was based on the following criteria. Firstly, field experience provided a rich opportunity for applying e-portfolio. Secondly, assessment tasks in the form of an electronic portfolio were structured into the design and organization of field experience.

\section{Technology}

The "Mahara" e-portfolio system was chosen to supplement this study for two reasons. Firstly, the software is an existing available resource acquired by HKIEd. Secondly, Mahara is a fully featured open source electronic portfolio system designed to provide users with the tools to create a personal and professional, learning, development and showcasing environment. The system allows users to customize 
the e-portfolio and user interface to reflect their individual style and preference. The students serve as portfolio owners who have control over the material, design, and membership of their portfolio. Users create portfolios entries that showcase a collection of their accomplishments, evaluations, and reflections in a web-based environment.

\section{E-portfolio design}

The content of the e-portfolio for field experience focused on student reflections of and artefacts uploaded to the Mahara e-portfolio system. Students were required to upload their work which included posting video clips and assignments and capturing parts of their reflections or other evidences to justify their claims of 'improvement'. The pilot was seen as a shift from a traditional paper-based version to an electronic version in a multi-media format (e.g., video clips, sound files, electronic documents, etc.), serving as method for self-reflection on the student-teachers' teaching practicum. As part of the existing field experience assessment component at HKIEd, a completed block practice portfolio was required to be submitted together with a reflective journal after completion of the block practice. A template had specifically been created to provide a consistent structure for student-teachers to follow through in the construction and design of their e-portfolio entries. The template contained a sequence of steps and design layout for student-teachers to follow in creating their e-portfolio, including: 1) a record of student-teachers' activities in placement schools; 2) documents about student-teachers' work such as lesson plans, scheme of work, worksheets, etc.; 3) copies of supervision forms, feedback from supporting teachers and supervisors; and, 4) a reflective journal supported by different artefacts (i.e., video clips, sound files, electronic documents, etc.).

\section{Instrument development process}

An instrument was developed that tapped various aspects of the four components of the model: ATL, FPV, FIC, and TR. The result was the student e-portfolio ownership of learning questionnaire (SEOLQ). The survey instrument used in this study was developed from several sources, including instruments developed by other researchers and literature on ownership of learning and attitudes towards learning. The Moore and Benbasat (1991) development procedure was utilized to create and evaluate the SEOLQ instrument. The following 3-stage development process was used:

- Item creation - creating a pool of items to match each construct definition. The objective of this stage was to ensure content validity;

- Card sorting - using a total of four judges in two rounds to sort items into construct categories (scales), and then, examining judges' inter-rater reliabilities and their consistency of labelling these scales; and

- Instrument testing - administering the survey instrument with the objective of checking scale feasibility.

\section{Item creation}

The goal of item creation was to develop a pool of items that have content validity according to the definition of each construct (Bohrnstedt, 1970). The items for the SEOLQ instrument were generated from Milner-Bolotin's (2001) framework of ownership and literature on attitudes towards learning. The response scale for all items was a 7-point positively-packed Likert rating scale coded as, 7: Strongly Agree; 6: Moderately Agree; 5: Slightly Agree; 4: Neutral; 3: Slightly Disagree; 2: Moderately Disagree; 1: Strongly Disagree. This type of scale has been found effective in eliciting variance in responses when a positive response style is expected (Klockars \& Yamagishi, 1988).

\section{Card sorting}

The goals of the card sorting procedure were two-fold: 1) to assess the construct validity of the scales being developed; that is, ensure that the survey instrument developed reflected the concepts and theoretical assumptions of our framework, and 2) to attempt to identify any particular items which still may be considered ambiguous. Four judges were asked to sort the various items into construct categories in two sorting rounds. In the first round, the judges were not told what the labels or names of the underlying constructs were, but were instead asked to provide their own labels and definitions for the constructs they created. In the second round, the judges received cards that contained the items together with cards that contained the construct labels, and were instructed to sort the cards into the five 
predefined categories. Hence, confidence in the construct validity of the scales increased if the judges' definitions matched the scale's intent.

To assess the reliability of the sorting conducted by the judges, we used two different measurements. First, we measured the level of agreement in categorizing all 18 items and three categories of items across all four judges at one time, using Cohen's Kappa (Cohen, 1977). Kappa values exceeding .60 indicate that observed agreement between judges exceeds chance rates of agreement by a considerable margin (Landis $\&$ Koch, 1977). A second measurement of validity was the Item Placement Ratio which measured how many items were placed by the panel of judges for each round within the 'target' construct. This meant that we were able to measure the overall frequency with which the judges placed items within the intended theoretical constructs.

The four judges were presented with 18 items related to the three constructs. Judges were allowed to select "Not Applicable" if they could not put it in any category in Round 1 or if they believed the item did not fit any of the given categories in Round 2. The distribution of item placements for the first round is shown in Table 1 . The item placements for each construct ranged from $75 \%$ to $87 \%$, with one item being rated as not applicable once. The chance-adjusted rater inter-correlation score was $\kappa=.85$.

Table 1

Matrix of item placement - judge's classification of first round

\begin{tabular}{lcccccc}
\hline & I. & II. & III. & IV. & N/A & \% Hits \\
\hline I. Finding Personal Value (FPV) & $\mathbf{1 9}$ & 1 & 1 & 2 & 1 & 79 \\
II. Feeling in Control (FIC) & 2 & $\mathbf{1 8}$ & 2 & 2 & 0 & 75 \\
III. Taking Responsibility (TR) & 1 & 1 & $\mathbf{2 1}$ & 1 & 0 & 87 \\
IV. Attitudes Towards Learning (ATL) & 2 & 0 & $\mathbf{2}$ & $\mathbf{2 0}$ & 0 & 83 \\
\hline
\end{tabular}

Note. Diagonal agreement shown in bold.

Revisions were made to those items that were "off-diagonal". The revised items were then subjected to a second round with a new set of four judges (Table 2). None of the items were rated as "Not Applicable" and the lowest place rate per construct was $87 \%$. Hence, the item revisions were deemed to be successful and the results demonstrated that items were aligned with the intended constructs.

Table 2

Matrix of item placement-judge's classification of second round

\begin{tabular}{lcccccc}
\hline & I. & II. & III. & IV. & N/A & \% Hits \\
\hline I. Finding Personal Value (FPV) & $\mathbf{2 3}$ & 1 & 0 & 0 & 0 & 95 \\
II. Feeling in Control (FIC) & 1 & $\mathbf{2 2}$ & 1 & 0 & 0 & 91 \\
$\begin{array}{l}\text { III. Taking Responsibility (TR) } \\
\begin{array}{l}\text { IV. Attitudes Towards Learning } \\
\text { (ATL) }\end{array}\end{array}$ & 0 & 1 & $\mathbf{2 2}$ & 1 & 0 & 91 \\
\hline
\end{tabular}

Note. Diagonal agreement shown in bold.

Data collection

A web-based version of the student e-portfolio ownership of learning questionnaire (SEOLQ) was administered to 77 students to fill out, wherein the order of items was randomized. A total number of 77 questionnaires were filled out resulting in a response rate of $100 \%$. The data collected from 77 responses was analysed to provide evidence for the validity and reliability of the SEOLQ. With a sample size of 77, the study had a power of 0.91 to yield a statistically significant result, exceeding .80 , a commonly accepted threshold in these analyses (Cohen, 1977). 


\section{Data analysis}

\section{Construct validity}

To test the construct validity of items in the instrument, confirmatory factor analysis was performed and reliability of factors assessed using Cronbach's (1970) alpha. Construct validity was assessed using confirmatory factor analysis (CFA) to test the fit of the data to the model. Table 3 presents the factor loadings of the E-Portfolio Ownership of Learning Questionnaire (SEOLQ) for the sample using the individual student as the unit of analysis. The results of confirmatory factor analysis indicated that the scales were not only reliable, but also valid for the factors under study.

Table 3

Constructs, items, and loading statistics

\begin{tabular}{|c|c|c|}
\hline Constructs & Items & $\begin{array}{l}\text { Factor } \\
\text { Loading }\end{array}$ \\
\hline \multicolumn{3}{|c|}{ Finding Personal Value (FPV) } \\
\hline FPV1 & Overall, I found constructing the e-portfolio valuable to my field experience. & 0.87 \\
\hline FPV2 & I acquired useful skills in creating my FE e-portfolio. & 0.80 \\
\hline FPV3 & $\begin{array}{l}\text { What I have learned from the FE e-portfolio in this course will benefit my } \\
\text { achievement in future courses. }\end{array}$ & 0.86 \\
\hline FPV4 & $\begin{array}{l}\text { Showcasing electronic media (i.e., text-based, graphic, or multi-media } \\
\text { elements) in my e-portfolio allowed me to demonstrate a more meaningful } \\
\text { understanding of my field experience. }\end{array}$ & 0.83 \\
\hline FPV5 & I was able to engage with the e-portfolio interface in a worthwhile manner. & 0.87 \\
\hline FPV6 & Overall, I valued the integration of the e-portfolio into this course. & 0.89 \\
\hline \multicolumn{3}{|c|}{ Feeling in Control (FIC) } \\
\hline FIC1 & I had control over which items in my e-portfolio other users could access. & 0.84 \\
\hline FIC2 & $\begin{array}{l}\text { Control over the e-portfolio content allowed me to showcase my best work } \\
\text { in a digitized format. }\end{array}$ & 0.82 \\
\hline FIC3 & $\begin{array}{l}\text { I could choose what artefacts to showcase in my e-portfolio for my field } \\
\text { experience. }\end{array}$ & 0.80 \\
\hline FIC4 & $\begin{array}{l}\text { I could exercise choice in how I customized my field experience e-portfolio } \\
\text { entry. }\end{array}$ & 0.86 \\
\hline FIC5 & $\begin{array}{l}\text { I was able to explore a variety of issues I might not have otherwise } \\
\text { considered through the e-portfolio I created. }\end{array}$ & 0.73 \\
\hline FIC6 & $\begin{array}{l}\text { I was allowed flexibility in how I organized my e-portfolio as a means of } \\
\text { showcasing my field experience performance. }\end{array}$ & 0.78 \\
\hline \multicolumn{3}{|c|}{ Taking Responsibility (TR) } \\
\hline TR1 & $\begin{array}{l}\text { I was provided with the appropriate training to assume responsibility for my } \\
\text { e-portfolio. }\end{array}$ & 0.71 \\
\hline TR2 & $\begin{array}{l}\text { I felt comfortable in taking initiative when presenting the contents in my } \\
\text { e-portfolio. }\end{array}$ & 0.87 \\
\hline TR3 & The e-portfolio helped me develop a sense of accountability for my learning. & 0.88 \\
\hline TR4 & $\begin{array}{l}\text { The process of creating my e-portfolio helped me to take responsibility for } \\
\text { my own learning. }\end{array}$ & 0.86 \\
\hline TR5 & Constructing the e-portfolio helped me to reflect upon my achievement. & 0.87 \\
\hline TR6 & $\begin{array}{l}\text { The use of the e-portfolio helped me evaluate my progress in the field } \\
\text { experience. }\end{array}$ & 0.87 \\
\hline \multicolumn{3}{|c|}{ Attitudes Towards Learning (ATL) } \\
\hline ATL1 & I enjoyed using the e-portfolio for my field experience. & 0.79 \\
\hline ATL2 & $\begin{array}{l}\text { I feel the e-portfolio is more convenient than traditional paper-based } \\
\text { portfolios. }\end{array}$ & 0.77 \\
\hline ATL3 & My knowledge of technology helped me when creating my e-portfolio. & 0.84 \\
\hline ATL4 & I would welcome the opportunity to use e-portfolios in future courses. & 0.83 \\
\hline ATL5 & $\begin{array}{l}\text { Overall, I have a favourable attitude towards using e-portfolio for my field } \\
\text { experience. }\end{array}$ & 0.85 \\
\hline ATL6 & $\begin{array}{l}\text { Overall, I am satisfied with the way my learning is assessed using the } \\
\text { e-portfolio in this course. }\end{array}$ & 0.71 \\
\hline
\end{tabular}


The factors were analysed using Cronbach's ALPHA (Cronbach, 1970). All of the measures employed in this study demonstrated excellent internal consistency, ranging from 0.87 to 0.94 (see Table 4), thereby exceeding the reliability estimates $(\alpha=0.70)$ recommended by Nunnally (1967).

Table 4

Cronbach ALPHA reliability coefficient

\begin{tabular}{lcc}
\hline \multicolumn{1}{c}{ Scale } & \# items & alpha \\
\hline I. Finding Personal Value (FPV) & 6 & 0.94 \\
II. Feeling in Control (FIC) & 6 & 0.89 \\
III. Taking Responsibility (TR) & 6 & 0.92 \\
IV. Attitudes Towards Learning (ATL) & 6 & 0.87 \\
\hline
\end{tabular}

\section{Discriminant validity}

Discriminant validity was assessed by inspecting the correlations between the five constructs (Bagozzi \& Phillips, 1991). Table 5 shows the Average Variance Extracted (AVE) for each construct and indicates that the questions for each construct correlated with each other than with those for the other constructs. Hence, the five constructs had good discriminant validity.

Table 5

Assessment of discriminant validity

\begin{tabular}{lllll}
\hline Construct & FPV & FIC & TR & ATL \\
\hline Finding Personal Value (FPV) & $\mathbf{. 3 3 1}$ & & & \\
Feeling in Control (FIC) & .112 &. $\mathbf{2 3 3}$ & & \\
Taking Responsibility (TR) & .221 & .185 & $\mathbf{. 5 6 9}$ & \\
Attitudes Towards Learning (ATL) & .148 & 0.97 & .245 & $\mathbf{. 3 0 5}$ \\
\hline
\end{tabular}

Note. Diagonal entries: average variance extracted; Non-diagonal entries: shared variance.

Table 6 shows a summary of the overall model fit measures. The goodness-of-fit indices for the model were: $\mathrm{GFI}=0.93$, AGFI $0.94, \mathrm{CFI}=0.97$ which meant that the goodness-of-fit index (GFI), adjusted goodness-of-fit index (AGFI) and the comparative fit index (CFI) of the proposed measurement model were well in the range of the suggested value of 0.90 (Bentler \& Bonnet, 1980). Similarly, NFI with values exceeding .9 indicate a good fit (Bentler \& Bonnet, 1980). These fit indices indicate that the proposed measurement model is satisfactory and suggest a good fit to the data. Hence, the results suggest the model provides a parsimonious fit to the data.

Table 6

Goodness-of-fit measures

\begin{tabular}{cc}
\hline Fit Measures & Values \\
\hline $\mathrm{X}^{2}$ & 207 \\
$R M R$ & 0.02 \\
RMSEA & 0.02 \\
$G F I$ & 0.93 \\
CFI & 0.97 \\
AGFI & 0.94 \\
NFI & .971 \\
\hline
\end{tabular}

Note. Comparative fit index (CFI), cut-off $>.90$. 


\section{Results}

Table 7 shows the intercorrelations between the constructs and their means and standard deviations. FPV was associated somewhat positively with FIC $(r=.22, \mathrm{p}<.001)$ and taking responsibility $(\mathrm{TR})(\mathrm{r}=-.70$, $\mathrm{p}<.001)$. There was also a significant positive correlation between FIC and TR $(\mathrm{r}=-.12, \mathrm{p}<.05)$. The relationship between ATL was associated somewhat positively with finding FPV $(\mathrm{r}=.19, \mathrm{p}<.001)$, FIC $(\mathrm{r}=.28, \mathrm{p}<.001)$ and TR $(\mathrm{r}=-.30, \mathrm{p}<.001)$.

Table 7

Correlation matrix

\begin{tabular}{lcccccc}
\hline & M & SD & $\mathbf{1}$ & $\mathbf{2}$ & $\mathbf{3}$ & $\mathbf{4}$ \\
\hline 1. FPV & 2.59 & 0.93 & $(.94)$ & & & \\
2. FIC & 3.28 & 0.71 & $\mathbf{. 2 2} * * *$ & $(.89)$ & & \\
3. TR & 3.67 & 0.85 & $\mathbf{- . 7 0} * * *$ & $\mathbf{- . 1 2 *}$ & $(.92)$ & \\
4. ATL & 2.79 & 0.76 & $\mathbf{. 1 9} * * *$ & $\mathbf{. 2 8 * * *}$ & $\mathbf{. 3 0 * * *}$ & $(.87)$ \\
\hline
\end{tabular}

Note. $\mathrm{n}=77$. Internal consistency reliabilities are given along the diagonal in parentheses.

$* \mathrm{p}<.05 . * * *<.001$.

To investigate the validity of this model to explain causal relational between ATL on FPV, FIC, and TR, the technique of path analysis was used (Woefle, 1980). This procedure is useful for examining hypothesized direct effects of constructs. A structural equation modelling (SEM) approach was used to develop a model that represents the relationships among the four factors in this study. Table 8 shows the results of the hypotheses tests by confirming the presence of a statistically significant relationship in the predicted direction of the proposed research model. Overall, all hypotheses were supported by the data. As shown in Figure 2, ATL, using e-portfolio, had a significant effect on finding FPV (path $=0.91$, $t$-value $=14.75, \mathrm{p}<0.01$ ), FIC (path=0.37, t-value $=2.22, \mathrm{p}<0.01$ ), and TR (path=0:83, t-value $=10.85, \mathrm{p}<0.01$ ), thus supporting all three hypotheses (see Table 6).

Table 8

Hypotheses testing results

\begin{tabular}{ccccc}
\hline Hypotheses & \multicolumn{1}{c}{ Path } & Path coefficient & t-value & Testing Result \\
\hline H1 & ATL $\rightarrow$ FPV & 0.91 & $14.75^{*}$ & Supported \\
H2 & ATL $\rightarrow$ FIC & 0.37 & $2.22^{*}$ & Supported \\
H3 & ATL $\rightarrow$ TR & 0.83 & $10.85^{*}$ & Supported \\
\hline
\end{tabular}

Note. *denotes $p<.01$ 


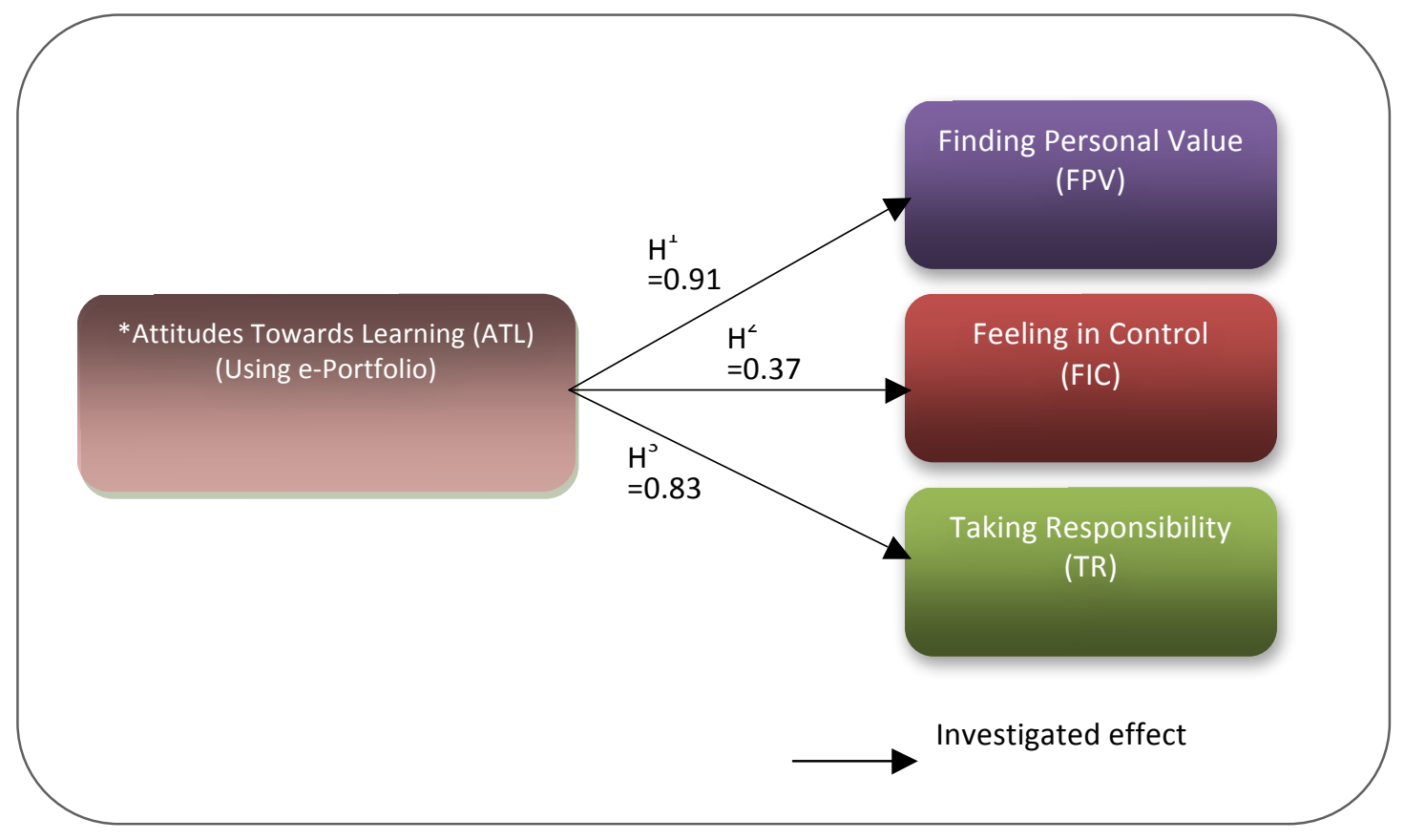

Figure 2. Path coefficient research model results.

\section{Discussion}

With reference to hypothesis 1 , the data indicated that ATL using e-portfolio had a significant effect on FPV. In general, we found that ATL using e-portfolio developed out of student-teachers' innate desire to achieve success in the e-portfolio in this study. Finding personal value can be described as a general desire to engage in the e-portfolio in a worthwhile manner, thus allowing student-teachers to demonstrate a more meaningful understanding of their field experience. It is interesting to note the attitudes of the subjects in this study - they seemed proficient, skilful, enthusiastic and adept at the use of the e-portfolio and seemed to enjoy interacting with the technology. The e-portfolio seemed to provide a sense of value, because showcasing the electronic media (i.e. text-based, graphic, or multi-media elements) in the e-portfolio entries allowed the student-teachers to demonstrate a more meaningful understanding of their field experience placement and subsequently benefit their achievement in future courses. The desire to be effective in the construction of e-portfolios may be the same as the desire to learn, improve individual skills and create more of a tendency to strive for success (Lin, 2008). Thus, we observe that finding value in an activity comes from positive attitudes of an individual in that activity (Deci \& Ryan, 1985). Value is an essential facet of ownership of learning, and the subjects within this study entered these learning contexts with varying levels of attitudes towards their learning using e-portfolios.

With reference to hypothesis 2 , the data indicated that ATL using e-portfolio had a significant effect on FIC. In this study, subjects were able to experience a degree of control over their e-portfolio, providing them with flexibility and discretion over the e-portfolio content, and thus allowing them to showcase their best work in a digitized format. For example, subjects could choose what artefacts to showcase in their e-portfolio and subsequently exercise choice in how they customized their e-portfolio entries. Prior research has focused on situational factors, such as control, that can alter an individual's subjective assessment during task performances (Kwon, 2002). An individual can engage in an activity while perceiving it to be either compulsory or completely voluntary. Even though the activity may be compulsory, the extent to which an individual chooses to participate in that activity is an important factor for engagement with e-portfolio. In this study, the use of e-portfolio encouraged the construction of knowledge through reflection. More specifically, Perlmuter and Monty (1971), claimed that feeling in control leads to improved performance, by increasing stimulation and sharpening cognitive engagement, in all aspects of the task. This interpretation fits in well with the findings in this study that the e-portfolio 
provided a sense of control - student-teachers' attitudes towards learning using e-portfolio intensified the drive to perform well, enhancing individual confidence and producing a heightened perception of control. With reference to hypothesis 3, the data indicated that ATL using e-portfolio had a significant effect on TR. In this study, subjects were able to experience a degree of responsibility by being provided with the appropriate training to assume responsibility for construction of their e-portfolio entries. Attitudes towards learning resonated strongly with taking responsibility and could be seen as critical to students positioning themselves as self-motivated stakeholders in their own education.

Responsibility-related findings suggest that participants were sensitive to both the means of manipulating the e-portfolio and the results of their efforts doing so. Taken together, this suggests that the means of engaging student-teachers in e-portfolio development must provide flexibility to learners, building a rich picture of ICT competency as well as emphasis on learner's reflection and personal development processes. Integrating both course design and e-portfolio functionality enabled better understanding by student-teachers of the potential of an e-portfolio to assist learning and evidence of their progress. If use of an e-portfolio is seen by students as an integral part of engaging with the course, then its benefits will be apparent in terms of what it can enable students to do more effectively. Any closer integration of course design and e-portfolio function would benefit from support and training of students and teaching staff (Reardon, Lumsden, \& Meyer, 2005).

\section{Limitations and Future Research Directions}

Rigorous statistical analysis was performed but the results are based on students' one snapshot perceptions. It would be more convincing if multiple data collection methods were used to provide a triangulation analysis of Milner-Bolotin's (2001) framework. Future direction could include: 1) examining the artefacts that students have submitted to counter check their perceptions for ownership of learning; 2) conducting focus group interviews to understand the impact different factors have on creating e-portfolios; 3) having a more diverse group of student teachers to further examine the validity of the results; and 4) administering the same research instrument with a control group to examine if student teachers have similar perceptions when engaging with paper-based portfolios.

\section{Conclusion}

The purpose of this study was to construct a more comprehensive ownership of learning model applied in an e-portfolio paradigm by examining student-teachers' attitudes towards learning in relationship to personal value, feeling in control and taking responsibility in a field experience placement. By integrating the construct of attitudes towards learning into Milner-Bolotin's (2001) framework of ownership, the results of this study showed that student-teachers' ATL using e-portfolio had a significant influence on their sense of PV, FIC and TR. Based on the results of this study, we can infer that when student-teachers have favourable attitudes towards learning, using e-portfolio, they may perceive a greater sense of value in constructing their e-portfolio entries, thereby allowing them to demonstrate a more meaningful understanding of their field experience. Likewise, we can also infer that when student-teachers' have favourable attitudes towards learning, using e-portfolio, they may perceive a greater sense of feeling in control over content, allowing them to showcase their best work in a digitized format and having control over which items in their e-portfolio other users can access. Similarly, we can also infer that when student-teachers' have favourable attitudes towards learning, using e-portfolio, they may perceive a greater sense of taking responsibility, allowing them to taking initiative when presenting the contents in their e-portfolio, thus developing a sense of accountability for their learning and being able to evaluate their progress in their field experience.

\section{References}

Abrami, P. C., \& Barret, H. (2005). Directions for research and development on electronic portfolios. Canadian Journal of Learning and Technology 31(3), 1-15.

Ajzen, I., \& Fishbein, M. (1980). Understanding attitudes and predicting social behavior. Englewood Cliffs, NJ: Prentice-Hall. 
Al-Gahtani, S. S., \& King, M. (1999). Attitudes, satisfaction and usage: factors contributing to each in the acceptance of information technology. Behaviour \& Information Technology, 18(4), 277-297.

Armitage, U., Wilson, S., \& Sharp, H. (2004). Navigation and ownership for learning in electronic texts: An experimental study. Electronic Journal on eLearning, 2(1), 19-30.

Ayala, J. I. (2006). Electronic Portfolios for Whom? Educause Quarterly, 29(1), 12-13.

Bagozzi, R. P., \& Phillips, L. W. (1991). Assessing construct validity in organizational research. Administrative Science Quarterly, 36(3), 421-458.

Bauer, W., \& Dunn, R. E. (2003). Digital reflection: The electronic portfolio in music teacher education. Journal of Music Teacher Education, 13(1), 7-20.

Bentler, P. M., \& Bonnet, D. (1980). Significance tests and goodness of fit in the analysis of covariance structures. Psychological Bulletin, 88(3), 588-606.

Berg, M. H., \& Lind, V. R. (2003). Preservice music teacher electronic portfolios: Integrating reflection and technology. Journal of Music Teacher Education, 12(2), 18-28.

Bohrnstedt, G. W. (1970). Reliability and validity assessment in attitude measurement. In G. F. Summers (Ed.), Attitude measurement (pp. 80-99). Chicago, Illinois: Rand-McNally.

Brown, K. W., \& Ryan, R. M. (2004). Fostering healthy self-regulation from within and without: A self-determination theory perspective. In A. Linley \& S. Joseph (Eds.), Positive psychology in practice (pp. 105-124). Hoboken, NJ: Wiley.

Cambridge, D. (2010). E-portfolios for lifelong learning and assessment. San Francisco: Jossey-Bass.

Chau, J., \& Cheng, G. (2010). Towards understanding the potential of e-portfolios for independent learning: A qualitative study. Australasian Journal of Educational Technology, 26(7), 932-950.

Cohen, J. (1977). Statistical power analysis for the behavioral sciences. (Rev. ed.). New York: Academic Press.

Cronbach, L. (1970). Essentials of psychological testing (3rd ed.). New York: Harper \& Row.

deCharms, R. (1968). Personal causation: the internal affective determinants of behavior. New York: Academic.

Deci, E. L., \& Ryan, R. M. (1985). The general causality orientations scale: Self-determination in personality. Journal of Research in Personality, 19, 109-134.

Deci, E. L., \& Ryan, R. M. (1987). The support of autonomy and the control of behavior. Journal of Personality and Social Psychology, 53, 1024-1037.

Deneen, C., Shroff, R. H. (2010). E-Portfolio use in two Institutes of Higher Education: A Comparative Case Study. 5th International Conference on e-Learning, Universiti Sains Malaysia, 12-13 July 2010, Penang, Malaysia.

Dudley-Marlin, C., \& Searle, D. (1995). Who owns learning: Questions of autonomy, choice, and control. Portsmouth, New Hampshire: Heinemann Educational Books.

Ellsworth, J. Z. (2002). Using student portfolios to increase reflective practice among elementary teachers. Journal of Teacher Education, 53(4), 342-355. 
Enghag, M., \& Niedderer, H. (2007). Two dimensions of student ownership of learning during small-group work in physics. International Journal of Science and Mathematics Education, 6(4), 629-653.

Feather, N. T. (1992). Values, valences, expectations, and actions. Journal of Social Issues, 48, 109-124.

Gaide, S. (2006). ePortfolio: Supercharge Performance-Based Student Assessment. Distance Education Report, 10(2), 14-16.

Gatlin, L., \& Jacob, S. (2002). Standards-based digital portfolios: A component of authentic assessment for preservice teachers. Action in Teacher Education, 23(4), 35-42.

Goldsby, D. S., \& Fazal, M. B. (2000). Technology's answer to portfolios for teachers. Kappa Delta Pi Record, 36(3), 121-123.

Gulikers, J., Bastiaens, T., \& Martens, R. (2005). The surplus value of an authentic learning environment. Computers in Human Behavior, $21(3), 509$.

Hallam, G., \& Creagh, T. (2010). ePortfolio use by university students in Australia: A review of the Australian ePortfolio Project. Higher Education Research \& Development, 29(2), 179-293.

Herremans, I. M., \& Murch, R. (2003). Multidisciplinary decision making through experiential learning: Perspectives from practical trials. Innovative Higher Education, 28(1), 63-83.

Hussein, N. H. N. (2009). Students perspectives on the engagement of electronic portfolio as a tool in classroom instruction. Journal of Human Capital Development, 2(1), 53-64.

Iyengar, S. S., \& Lepper, M. R. (1999). Rethinking the value of choice: A cultural perspective on intrinsic motivation. Journal of Personality and Social Psychology, 76, 349-366.

Joyes, G., Gray, L., \& Hartnell-Young, E. (2010). Effective practice with e-portfolios: How can the UK experience inform implementation? Australasian Journal of Educational Technology, 26(1), 15-27.

Klockars, A. J., \& Yamagishi, M. (1988). The influence of labels and positions in rating scales. Journal of Educational Measurement, 25(2), 85-96.

Kong, S. C., Shroff, R. H., Hung, H. K. (2009). A web enabled video system for self reflection by student teachers using a guiding Framework. Australasian Journal of Educational Technology, 25(4), 544-558.

Kwon, H. (2002). Adaptability of Electronic Portfolio for Performance Assessment. Journal of Elementary Education Research, 12, 201-238.

Landis, J. R., \& Koch, C. G. (1977). The measurement of observer agreement for categorical data. Biometrics, 33, 159-174.

Liddell, M., \& Davidson, S. (2004). Student attitudes and their academic performance: Is there any relationship? Medical Teacher, 26, 52-56.

Lim, C. P. (2004). Integrating ICT in Education: A study of Singapore schools. Singapore: McGraw-Hill.

Lin, Q. (2008). Preservice teachers' learning experiences of constructing e-portfolios online. The Internet and Higher Education, 11, 194-200.

Lorenzo, G., \& Ittelson, J. (2005). An Overview of E-Portfolios. Educause Learning Initiative, 1, 1-27.

Mansvelder-Longayroux, D. D., Beijaard, D., \& Verloop, N. (2007). The portfolio as a tool for stimulating reflection by student teachers. Teaching and Teacher Education, 23, 47-62. 
Martens, R., Gulikers, J., \& Bastiaens, T. (2004). The impact of intrinsic motivation on e-learning in authentic computer tasks. Journal of Computer Assisted Learning, 20, 368-376.

Milner-Bolotin, M. (2001). The Effects of Topic Choice in Project-Based Instruction on Undergraduate Physical Science Students' Interest, Ownership, and Motivation. University of Texas at Austin, Austin.

Moore, G., \& Benbasat, I. (1991). Development of an instrument to measure the perceptions of adopting an information technology innovation. Information Systems Research, 2(3), 192-222.

Murphy, P. K., \& Alexander, P. A. (2000). A motivated exploration of motivation terminology. Contemporary Educational Psychology, 25, 3-53.

Nichol, D., \& Macfarlane-Dick, D. (2006). Formative assessment and self-regulated learning: A model and seven principles of good feedback practice. Studies in Higher Education, 31(2), 199-218.

Nunnally, J. (1967). Psychometric theory. New York: McGraw-Hill.

O'Neill, T., \& Barton, A. C. (2005). Student ownership in an urban middle school science video project. School Science and Mathematics, 105(6), 292-302.

Ocker, R., \& Yaverbaum, G. J. (2002). Collaborative learning environments: Exploring student attitudes and satisfaction in face-to-face and asynchronous computer conferencing settings. Journal of Interactive Learning Research, 12(4), 427-448.

Orland-Barak, L. (2005). Portfolios as evidence of reflective practice: What remains 'untold'. Educational Research, 47(1), 25-44.

Pelliccione, L., \& Raison, G. (2009). Promoting the scholarship of teaching through reflective e-portfolios in teacher education. Journal of Education for Teaching, 35(3), 271-281.

Perlmuter, L. C., \& Monty, R. A. (1971). Effect of choice on paired-associate learning. Journal of Experimental Psychology, 91, 47-53.

Rainer, J. D., \& Matthews, M. W. (2002). Ownership of learning in teacher education. Action in Teacher Education, 24(1), 22-30.

Reardon, R. C., Lumsden, J. A., \& Meyer, K. E. (2005). Developing an e-portfolio program: Providing a comprehensive tool for student development, reflection, and integration. NASPA Journal, 42(3), 368-380.

Reeve, J., Nix, G., \& Hamm, D. (2003). Testing models of the experience of self-determination in intrinsic motivation and the conundrum of choice. Journal of Educational Psychology, 95(2), 375-392.

Rogers, C., \& Freiberg, H. J. (1994). Freedom to learn. New York: Macmillan/Merrill.

Savery, J. R. (1996). Fostering student ownership for learning. Indiana University, Bloomington IN.

Scardamalia, M., \& Bereiter, C. (1994). Computer Support for Knowledge-building communities. Journal of the Learning Sciences, 3(3), 265-283.

Schön, D. A. (1987). Educating the reflective practitioner. Toward a new design for teaching and learning. San Francisco: Jossey-Bass. 
Shroff, R. H., Deneen, C. C., \& Lim, C. P. (2012). Using e-portfolios to enhance student-teacher ownership of learning in career development. Paper presented at the American Educational Research Association (AERA) Annual Meeting.

Shroff, R. H., Ng, E. M. W., \& Deneen, C. (2011). An analysis of the technology acceptance model in examining students' behavioral intention to use an electronic portfolio system. Australasian Journal of Educational Technology, 27(4), 600-618.

Shroff, R. H., \& Deneen, C. C. (2011). Assessing online textual feedback to support student intrinsic motivation using a collaborative text-based dialogue system: A Qualitative Study. International Journal on E-Learning, 10(1), 87-104.

Shroff, R. H., Vogel, D. (2009). Assessing the Factors Deemed to Support Individual Student Intrinsic Motivation in Technology Supported Online and Face-to-Face Discussions. Journal of Information Technology Education, 8, 59-85.

Singleton, A., \& Newman, K. (2009). Empowering students to think deeply, discuss engagingly, and write definitively in the university classroom. International Journal of Teaching and Learning in Higher Education, 20(2), 247-250.

Stefani, L., Mason, R., \& Pegler, C. (2007). The educational potential of e-portfolios: Supporting Personal Development and Reflective Learning. London: Routledge.

Thompson, C. E., \& Wankel, L. M. (1980). The effects of perceived activity choice upon frequency of exercise behavior. Journal of Applied Social Psychology, 10, 436-443.

Tosh, D., Light, T., Fleming, K., \& Haywood, J. (2005). Engagement with electronic portfolios: Challenges from the student perspective. Canadian Journal of Learning and Technology, 31(3), 89-110.

Trent, J., Shroff, R. H. (2012) Technology, identity, and community: The role of electronic teaching portfolios in becoming a teacher. Technology, Pedagogy and Education, 1-18.

Tubaishat, A., Lansari, A., \& Al-Rawi, A. (2009). E-portfolio Assessment System for an Outcome-Based Information Technology Curriculum. Journal of Information Technology Education: Innovations in Practice, 8, 44-54.

Vogel, D. R., Davison, R., \& Shroff, R. H. (2001). Sociocultural learning: A perspective on GSS-enabled global education. Communications of the AIS, 7(9), 1-41.

Wade, A., Abrami, P. C., \& Sclater, J. (2005). An electronic portfolio to support learning. Canadian Journal of Learning and Technology, 31(3), 33-50.

Wang, M. C., \& Peverly, S. T. (1986). The self-instructive process in classroom learning contexts. Contemporary Educational Psychology, 11, 370-340.

Wang, S. K. (2009). E-Portfolios for integrated reflection. Issues in Informing Science and Information Technology, 6, 449-460.

Wickersham, L. E., \& Chambers, S. M. (2006). ePortfolios: Using technology to enhance and assess student learning. Education, 127(4), 738-746.

Woefle, L. M. (1980). Strategies of path analysis. American Educational Research Journal, 17, 183-210.

Wood, W. (2000). Attitude Change: Persuasion and Social Influence. Annual Review of Psychology, 51, 539-570.

Wright, V. H., Stallworth, B. J., \& Ray, B. (2002). Challenges of electronic portfolios: Student perceptions and experiences. Journal of Technology and Teacher Education, 10(1), 49-61. 
Zhang, S. X., Olfman, L., \& Ractham, P. (2007). Designing eportfolio 2.0: Integrating and coordinating web 2.0 services with eportfolio systems for enhancing users' learning. Journal of Information Systems Education, 18, 203-214.

Corresponding author: Ronnie H. Shroff, rshroff@ied.edu.hk

Australasian Journal of Educational Technology (C) 2013.

Please cite as: Shroff, R. H., Trent, J., \& Ng, E. M. W. (2013). Using e-portfolios in a field experience placement: Examining student-teachers' attitudes towards learning in relationship to personal value, control and responsibility. Australasian Journal of Educational Technology. 29(2), 143-160. 